\title{
Underdiagnosis and undertreatment of asthma in childhood
}

\author{
A N P SPEIGHT, D A LEE, E N HEY
}

\begin{abstract}
A total of 179 Tyneside children who had suffered at least one episode of wheeze since school entry were seen at the age of 7. All but 14 had visited a doctor for chest symptoms, but a diagnosis of asthma had been offered to the parents of only 21 children, including three of the 56 children experiencing four to 12 wheezy episodes a year and 11 of the 31 children experiencing more than 12 episodes a year. Bronchodilator treatment was rarely offered in the absence of such a diagnosis, and two thirds of the children had never received a bronchodilator. Of the children experiencing four or more episodes a year, only a third had received bronchodilator drugs regularly, though half had lost more than 50 days from school because of wheeze. School absenteeism fell 10-fold in the 31 children finally offered continuous prophylactic treatment. Although many doctors had feared that use of the word "asthma" would cause anxiety, parents were uniformly relieved when given an explanation of their child's recurrent wheeze.

This study uncovered a disturbing amount of ill health in children that was easily rectified. Probably this same problem exists in other areas.
\end{abstract}

Children's Clinic, Royal Victoria Infirmary, Newcastle upon Tyne A N P SPEIGHT, MRCP, first assistant in child health

E N HEY, FRCP, paediatrician

Preston Hospital, North Shields, Tyne and Wear NE29 OLR D A LEE, MB, BS, paediatric research registrar

Correspondence to: Dr E N Hey, Princess Mary Maternity Hospital, Great North Road, Newcastle upon Tyne NE2 3BD.

\section{Introduction}

Asthma is one of the commonest disorders of childhood. Between $10 \%$ and $12 \%$ of children suffer episodes of wheezing severe enough to seek medical attention. ${ }^{1}$ Previous studies have usually concentrated on the prevalence and course of the condition and have not questioned how well asthma is being diagnosed and managed in the community. A study of clinic referrals ${ }^{2}$ concluded that confusion over terminology and a longstanding belief that the term "asthma" should be avoided when talking to parents might be responsible for much underdiagnosis and undertreatment. We have tested this assumption by looking at management in the children identified by a recent community survey.

\section{Subjects and methods}

A survey of all the 2700 children in their third year of school in North Tyneside disclosed that $11 \%$ had wheezed since starting school. ${ }^{1}$ Two thirds of the children with wheeze since school entry were selected for more detailed study. Special attention was paid to the severity, duration, and frequency of the wheezing episodes, to the diagnostic label, and to the treatment that had been offered. Episodes of wheeze lasting less than one hour were ignored.

Parental statements about previous treatment were checked against general practice records in a random sample of one fifth of the children in the survey. Parental recall was substantially correct in nearly every case, but two mothers were unaware that their children had, in fact, been given a bronchodilator. Similar checks were made with hospital records and with respect to estimates of school absenteeism. In every case recorded absenteeism (from all causes) was greater than the parents' estimate of absenteeism due to wheeze. No attempt was made to establish how often the parents had gained an accurate impression of the doctors' working diagnosis as this, in itself, was incompletely documented.

The parents were then offered a full explanation for the symptoms that they had observed. In the vast majority of cases this was to the effect that their child had a form of asthma, with a qualifying adjective 
such as "mild" when appropriate. This explanation was augmented by a special handout, which included information about the range and course of asthma, the treatments available, and advice on how to manage future attacks. Thirty eight of the children were follow $d$ up at a special clinic with the consent of the general practitioner. Brief follow up helped to clarify the diagnosis and define the severity of the symptoms in a few cases, and a longer period of follow up helped to assess the response to additional treatment in some of the more severely affected children. A quarter of all the families were also reinterviewed a year later by an independent part time social worker to determine whether the parents had been upset when told that their child had asthma and to discover how much of the information given during the survey had been remembered and understood.

\section{Results}

Of the 179 children studied because of a history of wheeze since school entry, 29 had had no symptoms for more than a year. The remaining children were divided into different groups depending on the frequency of their episodes of wheeze (table I). All 10 children whose symptoms were adequately controlled by continuous prophylactic treatment at the time of the survey had had more than 12 episodes of wheeze in the year before starting this treatment and were therefore classified as having frequent symptoms, as were the children with continuous low grade symptoms.

\section{PREVIOUS DIAGNOSES}

In each case the mother was asked for her understanding of the general practitioner's current "working diagnosis." Only 21 families said that they had been told their child had asthma, and six of these had been informed of the diagnosis after being referred to hospital. A further 25 children had attended hospital because of chest trouble without being so diagnosed, and 13 of these had frequent or recurrent symptoms. Only a third of the children experiencing over 12 episodes of wheeze a year had been labelled as having asthma (table I).

TABLE I-Frequency of symptoms in children with history of wheeze since school entry in relation to doctor's "working diagnosis" at age 7

\begin{tabular}{lccccccc}
\hline & & \multicolumn{4}{c}{ Diagnostic label } & \\
\cline { 3 - 6 } Grade & $\begin{array}{c}\text { Frequency of } \\
\text { symptoms in } \\
\text { past year }\end{array}$ & Asthma & $\begin{array}{c}\text { Wheezy } \\
\text { bronchitis } \\
\text { or chest } \\
\text { "allergy" diagnoses* }\end{array}$ & $\begin{array}{c}\text { Non- } \\
\text { specific }\end{array}$ & $\begin{array}{c}\text { Not seen } \\
\text { by a } \\
\text { doctor }\end{array}$ & Total \\
\hline Past & No episodes & 2 & 2 & 22 & 3 & 29 \\
Occasional & 4 episodes & 5 & 6 & 45 & 7 & 63 \\
Recurrent & $4-12$ episodes & 3 & 5 & 45 & 3 & 36 \\
Frequent & $>12$ episodes & 11 & 5 & 14 & 1 & 31 \\
\hline Total & & 21 & 18 & 126 & 14 & 179 \\
\hline
\end{tabular}

*See text.

Twelve children had been diagnosed as having wheezy bronchitis and six an "allergic" chest condition, but 126 families had never been offered a diagnosis that included any explicit recognition of the child's wheeze. These children were classified as having "non-specific" diagnoses; 60 had been labelled as having recurrent bronchitis or "chestiness," and 23 as having recurrent colds or viral infections. The mothers of the remaining 43 children could not remember ever being offered any diagnosis. Fourteen families had never consulted a doctor for their child's symptoms, and a quarter of these children had frequent or recurrent wheeze.

\section{PREVIOUS TREATMENT}

Two thirds of the children had never been given a bronchodilator drug, and this was true of a third of the children having more than 12 episodes of wheeze a year (table II). All but one of the children labelled as having asthma regularly used a bronchodilator when symptoms appeared, as compared with only half of the children labelled as having wheezy bronchitis or an allergic chest condition and less than a fifth of those given a non-specific diagnosis (table III). Antibiotics were given regularly to $85 \%$ of the children who did not
TABLE II-Previous bronchodilator treatment in relation to symptom frequency in 7 year old children with history of wheeze since school entry

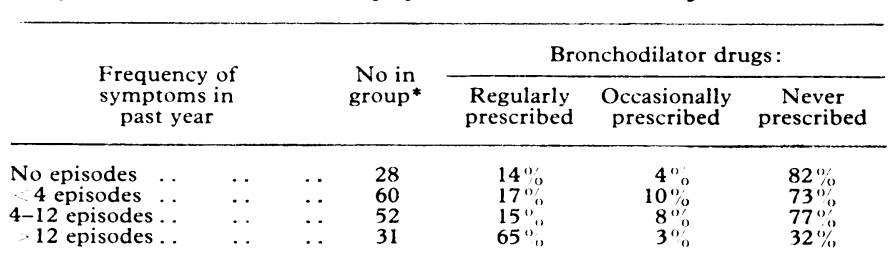

*Parents of eight children did not know whether bronchodilator had ever been prescribed.

TABLE III-Relation between previous diagnostic label and likelihood that bronchodilators had been prescribed in 165 children seen by doctor

\begin{tabular}{|c|c|c|c|c|}
\hline \multirow{2}{*}{$\begin{array}{c}\text { Diagnostic } \\
\text { label }\end{array}$} & \multirow{2}{*}{$\begin{array}{l}\text { No in } \\
\text { group* }\end{array}$} & \multicolumn{3}{|c|}{ Bronchodilator drugs: } \\
\hline & & $\begin{array}{l}\text { Regularly } \\
\text { prescribed }\end{array}$ & $\begin{array}{c}\text { Occasionally } \\
\text { prescribed }\end{array}$ & $\begin{array}{c}\text { Never } \\
\text { prescribed }\end{array}$ \\
\hline $\begin{array}{l}\text { Non-specific diagnoses } \\
\text { Wheezy bronchitis or }\end{array}$ & 120 & $13 \%$ & 9 & $78 \%$ \\
\hline $\begin{array}{lll}\text { "allergy" } & \ldots & \\
\text { Asthma } & \ldots & \ldots\end{array}$ & $\begin{array}{l}16 \\
21\end{array}$ & $\begin{array}{l}50 \% \\
95 \%\end{array}$ & $6 \%$ & $\begin{aligned} & 44 \% \\
& 5 \%\end{aligned}$ \\
\hline
\end{tabular}

*Parents of six children with non-specific chestiness and of two children with wheezy bronchitis or chest allergy did not know whether bronchodilators had ever been prescribed.

take a bronchodilator when ill but to only two of the 42 children who did use bronchodilators regularly.

Seventeen children had previously been prescribed disodium cromoglycate and four had also received beclomethasone. Hospital doctors were responsible for initiating treatment in half of these children. A quarter of the children, however, were apparently not getting full benefit from these drugs when seen because they did not realise how often they should take the drug.

The families who had been told that their children had asthma realised that this was a condition that might recur and had some idea of what to do if it did, but the other families had seldom been given any explanation for their child's problem or advice about its management, and many were extremely worried by its frequent recurrence. Many parents had also learnt to tolerate potentially dangerous attacks without calling a doctor or taking the child to hospital.

\section{DISABILITY}

Figure 1 shows the total amount of schooling lost due to wheeze since school entry. Sixty two children had lost more than 50 days of schooling due to wheeze. Also these children were probably handicapped to a similar extent at weekends and holidays, and to an even greater extent at night. School absenteeism from all causes at this age averages 16 days a year; hence over 50 of the wheezy children had had more than three times the usual amount of absenteeism.

A further eight children with frequent symptoms led very restricted lives without, however, missing much school. Parental tolerance of this handicap seemed to contribute to delay in diagnosis and treatment $N$ in some children. Cough may cause great distress in children with asthma, and this was the major complaint in at least a dozen children with mild intermittent wheeze. We have no doubt that the sleeplessness associated with severe cough led to further school absenteeism in addition to that documented in fig 1 .

\section{AVOIDABLE DISABILITY}

Ten children had begun effective prophylactic treatment in the year before the survey. A further 18 began continuous prophylactic treatment in the follow up clinic. The subsequent fall in school absenteeism (fig 2) confirms the belief that most children can lead a normal, unrestricted life with appropriate medical care. By the end of the survey 12 children were receiving cromoglycate and 19 beclomethasone $(0.7 \%$ and $1.2 \%$ of the sample population of 7 year olds respectively). No child was taking both drugs simultaneously. All the children who ended up taking beclomethasone had been inadequately controlled by cromoglycate.

The main therapeutic measure adopted in the children not followed

.
(n) 


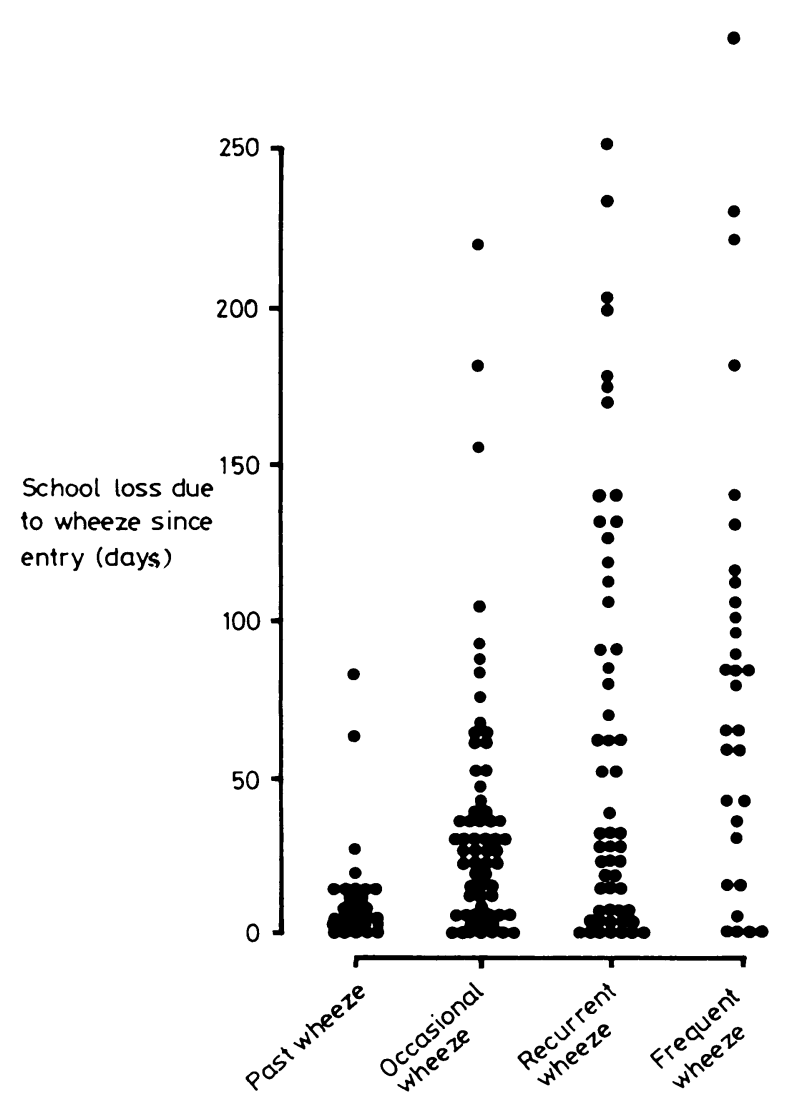

FIG 1-Total school absence due to wheeze in relation to frequency of symptoms at time of survey (definitions as in table I).

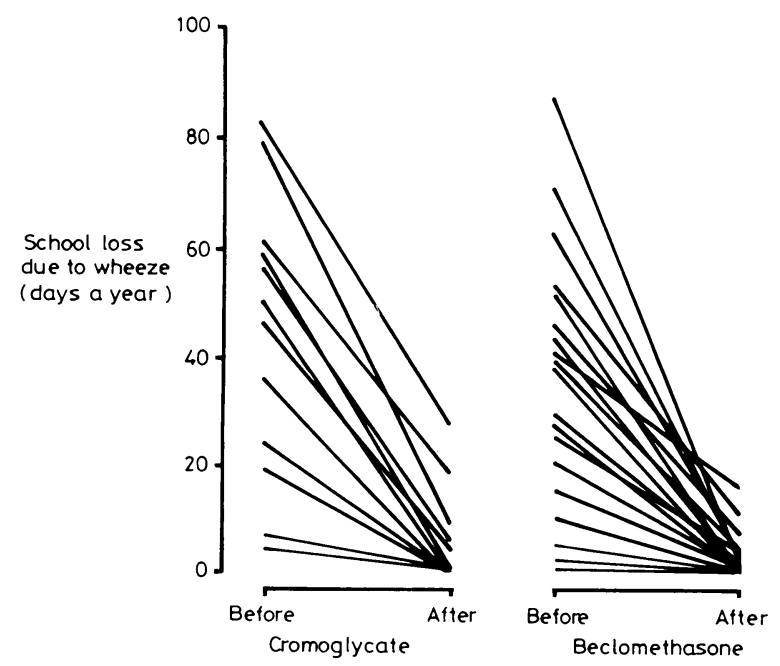

FIG 2-Reduction in school absence due to wheeze in response to continuous prophylactic treatment.

up was to ensure that the child received bronchodilator treatment in future attacks. One hundred and eight families were advised to keep a supply of bronchodilator at home for immediate use if needed.

\section{FAMILY REACTIONS}

Families appeared to be uniformly relieved when first told that their child had asthma and given detailed advice about its management. Follow up assessment one year later by a social worker previously unconnected with the hospital or the survey amply confirmed this initial impression. Only one mother recalled being upset when first told her child had asthma, and she rapidly came to accept the diagnosis after a few weeks.

Recall was remarkably good in the $83 \%$ of families who remembered being given a written document explaining the nature of their child's condition and its management. Many couples remarked spontaneously that they could not understand why they had not been given this information before.

\section{Discussion}

Asthma is common and its treatment straightforward and rewarding. Treatment, however, depends on prior diagnosis, and we found a serious degree of underdiagnosis in Tyneside. A similar survey in south London recently came to much the same conclusion. ${ }^{3}$ The main responsibility for diagnosis and management must rest with the general practitioner, ${ }^{4}$ but the school medical service is ideally placed to screen children for this common and eminently treatable condition. Laboratory tests and special investigations are unnecessary for the diagnosis and management of most children. We found that over $96 \%$ of all children could be identified by the parents' reply to the single question, "Has your child ever had attacks of wheezing?" Diagnosis presents a problem only when doctors fail to ask specifically about wheeze when parents volunteer less helpful symptoms such as cough or chestiness, as children are often free of overt wheeze by the time they are seen.

Many practitioners are extremely reluctant to label young children as asthmatic. This seems to affect their willingness to acknowledge the presence of bronchospasm and to treat it with bronchodilators. Failure to label a child as having asthma deprives parents of a rational explanation for their child's condition and an understanding of what the future may hold. It is also clearly linked with the doctor's failure to prescribe specific treatment. Even more serious, it leaves the child in real danger in any sudden severe attack, as it is difficult for parents to call an ambulance for "bronchitis" or "chestiness."

There appear to be two separate but related explanations for these phenomena. The first, and probably the more important, is the longstanding paediatric tradition that the word asthma should be used only as a last resort when dealing with young children who wheeze. This was originally to avoid needless parental anxiety. Whatever justification this teaching may have had in the past, it has outlived its usefulness and is now a block to rational treatment.

The second possible explanation for the underdiagnosis of asthma is the belief that wheezy bronchitis is a separate, definable clinical entity and not just a convenient euphemism for childhood asthma. Recent research has undermined this belief ${ }^{5}{ }^{6}$ and there seems little clinical value in trying to differentiate between the two conditions when management is identical. ${ }^{78}$ All too often the (viral) bronchitis is treated with antibiotics while the wheeze is ignored. Similar considerations almost certainly apply to the term "chronic bronchitis," which is often used to describe these children in North America. ${ }^{9}$

We found the amount of unnecessary ill health, unhappiness, and anxiety we uncovered most disturbing. Anyone who believes that similar problems do not exist in their own area should undertake a comparable study.

We are most grateful to the general practitioners of North Tyneside and to Dr W D Elliott, of Preston Hospital, North Shields, and Professor J K G Webb in Newcastle for their help and cooperation. We are also grateful to Mrs J Morgan for the follow up interviews. DAL was in receipt of a research fellowship from the Northern Regional Health Authority.

The preliminary results from this study were presented to the annual meeting of the British Paediatric Association in April 1980.

\section{References}

' Lee DA, Winslow NR, Speight ANP, Hey EN. Prevalence and spectrum of asthma in childhood. $\mathrm{Br}$ Med 7 1983;286:1258-60. 
2 Speight ANP. Is childhood asthma being underdiagnosed and undertreated? Br Med F 1978; ii :231-2.

${ }^{3}$ Anderson HR, Bailey PA, Cooper JS, Palmer JC. Influence of morbidity, illness label, and social, family, and health service factors on drug treatment of childhood asthma. Lancet 1981 ;ii:1030-2.

' Anonymous. Asthma-a challenge for general practice. 7 R Coll Gen Pract $1981 ; 31: 323-4$

${ }^{5}$ Williams H, McNicol KN. Prevalence, natural history, and relationship of wheezy bronchitis and asthma in children. An epidemiological study. Br Med f 1969;iv:321-5.
B Sibbald B, Horn MEC, Gregg I. A family study of the genetic basis of asthma and wheezy bronchitis. Arch Dis Child 1980;55:354-7.

${ }^{7}$ Lenney W, Milner AD. Recurrent wheeze in the preschool child. Arch Dis Child 1978;53:468-73.

${ }^{8}$ Gregg I. The role of viral infections in asthma and bronchitis. In: Proudfoot AT, ed. Symposium: viral diseases. Edinburgh: Royal College of Physicians of Edinburgh, 1975. (Publication No 46.)

9 Taussig LM, Smith SM, Blumefeld R. Chronic bronchitis in childhood: what is it? Pediatrics $1981 ; 67: 1-5$

(Accepted 9 February 1983)

\title{
Prevalence and spectrum of asthma in childhood
}

\author{
D A LEE, N R WINSLOW, A N P SPEIGHT, E N HEY
}

\begin{abstract}
All the 7 year old schoolchildren in North Tyneside were screened for wheeze with a questionnaire followed by selective clinical assessment: $9 \cdot 3 \%$ of the children had had episodic wheeze within the past year and all those followed up subsequently responded to one or more of the drugs used for asthma. A further $1.8 \%$ had had similar symptoms since starting school, though they had not wheezed in the past year. Frequency of symptoms in the $11 \%$ of children with features of asthma varied widely and correlated with bronchial reactivity on histamine challenge, but it was not possible to separate children with frequent wheeze from asymptomatic controls by their response to histamine.
\end{abstract}

It was concluded that all these wheezy children had symptoms of a common basic disorder and that they should all be treated as asthmatic.

\section{Introduction}

Estimates of the prevalence of asthma in childhood vary widely. ${ }^{\prime}$ Some authors report point prevalence (or the number of children currently experiencing symptoms), while others report cumulative prevalence. More important, some authors include only children diagnosed as having asthma, whereas others include children with recurrent episodic wheeze who have never been given a specific diagnosis. Some authors include children having had a single episode of wheeze; others include only children who have had several attacks of indeterminate duration and severity. Many have accepted an uncorroborated parental report of wheeze, but we find that some parents confuse croup, stridor, dyspnoea, and nocturnal snoring with wheeze. We have sought a way around this confusion by seeing each child individually and monitoring the response to bronchodilators in a population sample of 7 year olds currently experiencing episodic wheeze.

Preston Hospital, North Shields NE29 0LR

D A LEE, MB, BS, paediatric research registrar

N R WINSLOW, BMEDSCI, medical student

Children's Clinic, Royal Victoria Infirmary, Newcastle upon Tyne NE1 4LP

A N P SPEIGHT, MRCP, first assistant in child health

E N HEY, FRCP, paediatrician

Correspondence to: Dr E N Hey, Princess Mary Maternity Hospital, Great North Road, Newcastle upon Tyne NE2 3BD.

\section{Subjects and methods}

Screening-All children in the third year of school in North Tyneside were screened for "chest trouble" by questionnaire during the first eight months of 1979, when they were about 7 years old. The questionnaire sought to uncover symptoms, rather than diagnoses, and the terms asthma and wheezy bronchitis were not used. The key question was, "Has your child ever had attacks of wheezing ?" There were also three supplementary questions about recurrent nocturnal cough, sudden shortness of breath, and wheezing or shortness of breath on exercise. Parents were told that wheezing meant noisy breathing with a whistling quality coming from the chest and not just the throat and asked to answer "yes," "no," or "not sure" to each of the questions. Independent validation of the questionnaire in 450 children aged 7-8 years confirmed that a positive response to the questions on spontaneous wheeze and cough and wheeze on exercise identified all the children with wheeze in the past year and all but one of the children with wheeze since school entry. It identified only about two fifths of children who had stopped wheezing after the first two or three years of life, but we expected this because the covering letter made it clear that the survey was primarily concerned to identify children with current chest trouble.

Assessment-Twoout of three of the children who reported symptoms since starting school at 5 were selected at random, and $88 \%$ of these were eventually assessed individually along with 100 control children also selected at random. A full clinical history was taken from each mother and the child subjected to physical examination, basic spirometry with a McDermott spirometer, and a histamine challenge test. Skin tests were not performed but specific questions were asked to determine whether the child had any other evidence of an atopic tendency. The findings were discussed with the parents after the lung function and histamine challenge tests were complete. The general practitioner was also fully briefed on the outcome of the examination.

Histamine challenge tests were performed in the presence of a parent by someone who had not been told about the child's medical history. Doubling concentrations of histamine acid phosphate were offered until there was more than a $20 \%$ fall in forced expiratory volume in one second three minutes after taking five maximum inspiratory breaths of the nebulised histamine over 15-30 seconds. ${ }^{2}$ That the fall was real was then confirmed by immediately reversing it with nebulised salbutamol. The maximum concentration used contained $16 \mathrm{~g}$ histamine acid phosphate per litre. No child developed any respiratory distress as a result of this test procedure and only one became tearful for a brief period.

Follow $u p$-In 38 cases where there remained any doubt about the diagnosis or the efficacy of current treatment we obtained the consent of the general practitioner to follow up the child at home, using a diary card and peak flow meter, until it was established that the child had a condition that responded satisfactorily to bronchodilator drugs, inhaled cromoglycate, or beclomethasone. Sixty other children who had not been diagnosed as having asthma before the survey were also reassessed after a year by a social worker previously unconnected with the survey. Forty families were selected at random and interviewed to determine how the family had reacted to being told that their child had asthma. These and a further 20 families who had a child with 